\title{
Loneliness, Self Esteem and Depression among Elderly People of Kashmir
}

\author{
Aijaz Ahmad ${ }^{1} *$, Mohd. Altaf ${ }^{2}$, Kounsar Jan $^{3}$
}

\section{ABSTRACT}

India is gradually turning into graying nation. With increased life expectancy there is more number of citizens above 60-65 age range now. However the changes that come in later life retirement, death of spouse, increased isolation - can lead to different psychological problems among which depression is quite common. At the same time, studies indicate that loneliness, self esteem are potent factors involved in such psychological problems. The present study was undertaken to find the relation of such factors on depression in elderly Kashmiris as well as their presence in different sections. The sample consisted of 100 old age retired persons taken from different districts of Kashmir. Geriatric Depression Scale, Rosenberg's Self -Esteem Scale, and UCLA loneliness Scale were applied on the participants to collect the data. Spss 20 was used to analyse the data and results revealed significant positive as well as negative correlation among different variables. However no significant differences were found across gender and domicile of participants on any of the measure. Hence it is clear that there is relation of depression with lonliness and self-esteem, however the nature and the direction of effect is not fully established.

Keywords: Self-esteem, loneliness, Depression, Elderly, Kashmir.

Ageing is a continuous process beginning at the time of conception and ending with death. It is the process of becoming older, a process that is genetically determined and environmentally modified. However the period of old age is a time of challenge exemplified by changes in roles such as becoming a grandparent, retirement and other significant life events such bereavement, and potential reductions in social network and support (Dahlberg, Andersson, McKee, \& Lennartsson, 2015). It can also mean ill-health, reduced mobility of self which may compromise opportunities to develop new friendships or maintain existing relationships (Van Baarsen, Snijders, Smit, \& Van Duijin, 2001). One common psychological effect of it is loneliness which

\footnotetext{
${ }^{1}$ Clinical Psychologists, Dept. Of Psychiatry, Govt. Medical College, Srinagar, Kashmir, India

${ }^{2}$ Clinical Psychologists, Dept. Of Psychiatry, Govt. Medical College, Srinagar, Kashmir, India

${ }^{3}$ PG Diploma in Rehabilitation Therapy, Srinagar, Kashmir, India

*Responding Author

(C) 2016 I A Ahmad, M Altaf, K Jan; licensee IJIP. This is an Open Access Research distributed under the terms of the Creative Commons Attribution License (http://creativecommons.org/licenses/by/2.0), which permits unrestricted use, distribution, and reproduction in any Medium, provided the original work is properly cited.
} 


\section{Loneliness, Self Esteem and Depression among Elderly People of Kashmir}

may be defined as the 'discrepancy between one's desired and achieved levels of social interaction' (Peplau \& Perlman, 1982). The person simultaneously lacks connection with other people and may result in a feeling of loneliness. Loneliness may occur in people of all ages, but it is believed to be a common and more serious problem for older people (Heylen, 2010). Loneliness is a condition with feelings of distress, depression and detachment due to a gaping emptiness in a person's social and/or emotional life (Lilleen, 1998). It is associated with cognitive decline, depression, stress and anxiety (Fratiglioni et al. 2000, Tilvis et al. 2000, Sevil et al. 2006). Self-esteem is commonly seen to be low in such people. Self esteem is is how we view ourselves positively or negatively, and our overall attitude towards oneself. The individual with low self-esteem, would not accept himself and assume that he is useless and needy. Rosenberg has suggested that low self esteem can lead to depression as a result of failure to obtain positive self- acceptance (Khaidzir \& Ong, 2007). Hence lonliness, self esteem and depression are intervened together. In present study, an attempt was made to look into these variables and their relation to one another in kashmiri elderly population with the objectives of comparing loneliness, self esteem and depression across gender and domicile as well as their intercorrelation. Loneliness and self esteem will be studied elderly people with and without depression.

\section{METHOD}

Sample: The present study consists of a sample of 100 old age retired persons taken from the parts of District Baramulla, Pulwama, Budgam, and Srinagar. Sample included both rural and urban participants who gave their consent within the age range of 50-70 years. All the participants had their partners alive at the time of sampling.

\section{Tools used:}

1. Geriatric Depression Scale (GDS): The questionnaire is fifteen item self report assessment used to identify depression in the elderly people. The scale was first developed in 1983 by Yesavage, Brink, Rose et al. The GDS is 30 item scale and questions are answered in "yes" or "no" fromat.

2. University of California LOS Angles loneliness Scale: This questionnaire is a 20 item scale developed by Russel, Peplau and Ferguson in 1978 and consists of twenty statements described on four point scale that ranged from "never" to "often". The measure has high internal consistency (coefficient alpha $=.96$ ) and a test-retest correlation over a two-month period of .73.

3. Rosenberg's Self-Esteem Scale: It is developed by Dr. Morris Rosenberg in 1965. The questionnaire is a ten item likert type scale with item answered on four response categories from "strongly disagree to strongly agree". This scale was originally validated on a large sample of high school students. Test - retest correlation are typically in the range of 0.82 to 0.88 and Cronbach's alpha for various samples are in the range of 0.77 to 0.88 . 
Procedure: The subjects were contacted personally in their homes and working places. They were given proper directions. The subjects were assured that their responses would be kept confidential and would be used for research purpose only. The questionnaires were distributed and necessary help was provided by the researchers where ever they needed. For achieving the objectives, the data collected was analysed by using various statistical techniques like central tendency measures (mean \& standard deviation ), t-test and parsons correlation.

\section{RESULTS AND DISCUSSION}

\section{Table 1: Socio demographic data of the sample.}

\begin{tabular}{|l|l|l|l|}
\hline Demographic Data & Groups & Frequency & Percentage \\
\hline \multirow{3}{*}{ Gender } & Male & 57 & 57 \\
\cline { 2 - 4 } & Female & 43 & 43 \\
\hline \multirow{2}{*}{ Aomicile } & Rural & 48 & 48 \\
\cline { 2 - 4 } & Urban & 52 & 52 \\
\hline \multirow{2}{*}{ Economic status } & $50-60$ yrs & 69 & 69 \\
\cline { 2 - 4 } & $60-70$ yrs & 31 & 31 \\
\hline & Upto 10000 & 22 & 22 \\
\cline { 2 - 4 } & $10000-20000$ & 58 & 58 \\
\cline { 2 - 4 } & $20000-30000$ & 20 & 20 \\
\hline
\end{tabular}

Table 2: Comparison of loneliness, self esteem and depression across Gender.

\begin{tabular}{|l|l|l|l|l|l|}
\hline & Gender & N & Mean & t-value & p-value \\
\hline \multirow{2}{*}{ Loneliness } & Male & 57 & 35.53 & \multirow{2}{*}{.43} & .67 \\
\cline { 2 - 4 } & Female & 43 & 33.44 & & \\
\hline \multirow{2}{*}{ Delf-esteem } & Male & 57 & 14.14 & \multirow{2}{*}{.06} & \multirow{2}{*}{.95} \\
\cline { 2 - 4 } & Female & 43 & 14.21 & \multirow{2}{*}{.28} & \multirow{2}{*}{.81} \\
\cline { 2 - 4 } & Male & 57 & 6.53 & & \\
\cline { 2 - 4 } & Female & 43 & 6.30 & & \\
\hline
\end{tabular}

Table 3: Comparison of loneliness, self esteem and depression across Domicile.

\begin{tabular}{|c|c|c|c|c|c|}
\hline & Domicile & $\mathbf{N}$ & Mean & t-value & p-value \\
\hline \multirow[t]{2}{*}{ Loneliness } & Rural & 48 & 31.85 & \multirow{2}{*}{1.12} & \multirow[t]{2}{*}{.265} \\
\hline & Urban & 52 & 37.19 & & \\
\hline \multirow{2}{*}{$\begin{array}{l}\text { Self- } \\
\text { Esteem }\end{array}$} & Rural & 48 & 15.25 & \multirow{2}{*}{1.89} & \multirow[t]{2}{*}{.062} \\
\hline & Urban & 52 & 13.17 & & \\
\hline \multirow[t]{2}{*}{ Depression } & Rural & 48 & 5.79 & \multirow{2}{*}{1.38} & \multirow[t]{2}{*}{.171} \\
\hline & Urban & 52 & 7.02 & & \\
\hline
\end{tabular}




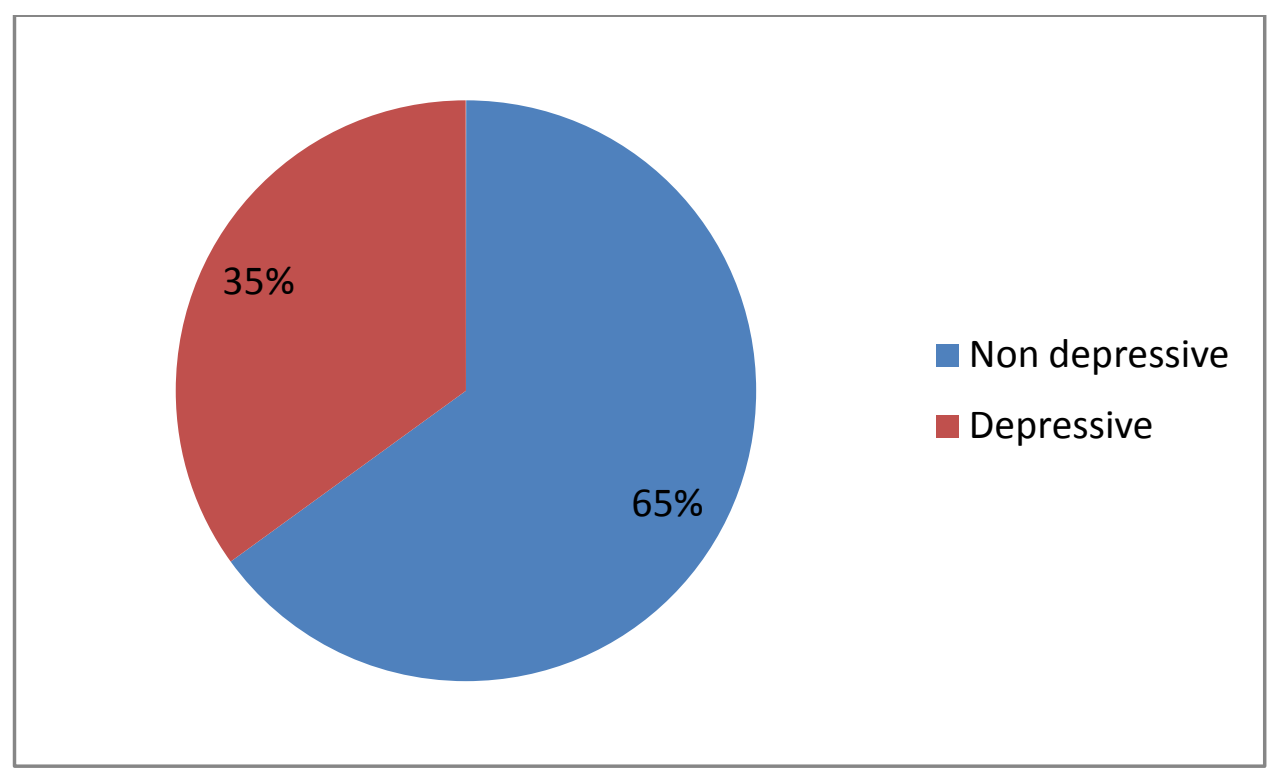

Fig 1: The prevalence of depressed and non depressed elderly people.

Table 4: Comparison of loneliness and self esteem across depressed and non depressed elderly people.

\begin{tabular}{|c|c|c|c|c|c|}
\hline \multirow{3}{*}{$\begin{array}{l}\text { Variable } \\
\text { Loneliness } \\
\end{array}$} & Groups & $\mathbf{N}$ & Mean & t- value & p-value \\
\hline & Non depressed & 65 & 21.72 & \multirow{2}{*}{10.95} & \multirow{2}{*}{.0001} \\
\hline & Depressed & 35 & 58.60 & & \\
\hline \multirow{2}{*}{ Self-esteem } & Non depressed & 65 & 16.60 & \multirow{2}{*}{7.38} & \multirow{2}{*}{.0001} \\
\hline & Depressed & 35 & 9.66 & & \\
\hline
\end{tabular}

Table 5: Inter-Correlation of different variable of the study.

\begin{tabular}{|l|l|l|l|l|}
\hline & Depression & Loneliness & Self-esteem & Income \\
\hline Depression & 1 & & & \\
\hline Loneliness & $.875^{* *}$ & 1 & & \\
\hline Self-esteem & $-.753^{* *}$ & $-.859^{* *}$ & 1 & \\
\hline Income & $-.660^{* *}$ & $-.729^{* *}$ & $.691^{* *}$ & 1 \\
\hline
\end{tabular}

In the present study, total of 100 elderly people were taken out of which 57 were male and 47 were female with slightly higher proportion of males. Domicile wise, sample was almost equally divided into rural and urban. However majority of the sample were falling in the age range of 5060years (69\%). Likewise on income basis, majority of the sample was from middle income range group of 10-20 thousand monthly (table 1). Comparison was made to find differences across gender and domicle on different variables like loneliness, self esteem and depression and it was found that the mean differences were not significant at .05 level of significance (Table $2 \& 3$ ). A study done in Ethiopia also revealed no significant sex difference on self-esteem, depression and

(C) The International Journal of Indian Psychology, ISSN 2348-5396 (e)| ISSN: 2349-3429 (p) | 150 


\section{Loneliness, Self Esteem and Depression among Elderly People of Kashmir}

loneliness (Yizengaw \& Ebiresilus, 2014). Similar results were reported by Halit (2014) who found no significant difference between levels of depression and gender of the elderly. Toha (2006) reported that depression is an emotional disorder that can happen to any person regardless of his or her gender, age, and socio-economic level. These findings reveal that the self- esteem of the elderly people is not affected by gender and they may have different views on self- esteem. Loneliness is two to three times more prevalent in elderly people with depression than in no depressed elders (Adams, et al, 2004; Stek, et al, 2005).

Further patients were categorised on the basis of presence or absence of depression in the sample. It was found that $35 \%$ were found to have depression on the geriatric depression scale (fig 1).

Later the two groups of depressed and no depressed elderly people were compared using t-test on the measures of loneliness and self esteem and it was found that there was significant difference on the measure of loneliness as well as on the measure of self esteem at .0001 level of significance (table 4). Lim \& Kua (2011) also reported that loneliness was a more robust predictor of depression score in their study. Lonely people suffer from more depressive symptoms and reported to be less happy, less satisfied and more pessimistic (Singh \& Kiran, 2013). Similarly self -esteem is related to low levels of depression, better health and overall greater success in life (Thomopoulou et al., 2010).

Different variables of the study were later correlated to find their correlation and it was found that some variables were significantly correlated together. Depression was positively and significantly correlated to loneliness but negatively correlated to self esteem and income. Similarly loneliness was found to have statistically significant negative correlation with self esteem and income but self esteem has positive correlation with income (table 5). Aylaz et al . (2012) also examined relationship between depression and loneliness in a sample of 913 elderly people and found significant correlation between loneliness and depression in elderly people. Wu \& zhang (2011) also reported eelderly well being to have connections with lonliness. Similar other studies reported statistically significant direct relationship of self-esteem with income level (Yizengaw, \& Ebiresilus, 2014). Hence significant relationship of loneliness and self-esteem with depression has already been reported in many studies (Toha, 2006; Nor Yaacob et.al., 2009; Halit, 2014). The exact nature of the association between depression and loneliness is not yet fully understood, (Cacioppo et al., 2006; Cacioppo et al., 2010) Although some studies report perceived (severe) loneliness as a gateway to depression (Barg et al., 2006). Several cross sectional studies of elderly people have shown that loneliness as one of the most important determinants of depressive symptoms (Alpass and Neville, 2003; Adams et al., 2004; Cacioppo et al., 2006). 


\section{Loneliness, Self Esteem and Depression among Elderly People of Kashmir}

\section{Acknowledgments}

The author appreciates all those who participated in the study and helped to facilitate the research process.

\section{Conflict of Interests}

The author declared no conflict of interests.

\section{REFERENCES}

Adams, K. B., Sanders, S. \& Auth, E. A. (2004). Loneliness and depression in independent living retirement communities: risk and resilience factors. Aging \& Mental Health, 8, 475-485.

Alpass, F. M. \& Neville, S. (2003). Loneliness, health and depression in older males. Aging \& Mental Health, 7, 212-216.

Aylaz, R., Akturk, U., Erci, B. Ozturk, H. \& Aslan, H. (2012). Relationship between depression and loneliness in elderly and examination of influential factors. Archives of Gerontology and Geriatrics, 55(3), 548-554.

Barbour, R. S.(2001). Checklists for improving rigour in qualitative research: a case of the tail wagging the dog? British Medical Journal, 322, 1115-1117.

Barg, F. K., Huss-Ashmore, R., Wittink, M. N., Murray, G. F., Bogner, H. R. \& Gallo, J. J. (2006). A mixed-methods approach to understanding loneliness and depression in older adults. Journals of Gerontology Series B: Psychological Sciences and Social Sciences, 61, S329-S339.

Cacioppo, J. T., Hawkley, L. C. \& Thisted, R. A. (2010). Perceived social isolation makes me sad: 5-year cross-lagged analyses of loneliness and depressive symptomatology in the Chicago Health, Aging, and Social Relations Study. Psychological Aging, 25, 453-463.

Cacioppo, J. T., Hughes, M. E., Waite, L. J., Hawkley, L. C. \& Thisted, R. A. (2006). Loneliness as a specific risk factor for depressive symptoms: cross-sectional and longitudinal analyses. Psychological and Aging, 21, 140-151.

Dahlberg, L., Andersson, L., McKee, K. J., \& Lennartsson, C. (2015). Predictors of loneliness among older women and men in Sweden: A national longitudinal study. Aging and Mental Health, 19, 409-41.

Fratiglioni, L., Wang, H. X., Ericsson, K., Maytan, M. \& Winblad, B. (2000). Influence of social network on occurrence of dementia: a community-based longitudinal study. Lancet 355, 1315-1319.

Halit, A. H. (2014) . Self Esteem and Its Relation to Depression among the Elderly. International journal of business and social science, 5(3), 266-273.

Heylen, L. (2010). The older, the lonelier? Risk factors for social loneliness in old age. Ageing \& Society 30, 1177-1196.

Khaidzir, H. J., \& Ong, L. L. (2007). The relationship between psikopathi, sikopatologi and self esteem in young girls. E - Bangi Journal, 2(2). ISBN: 1823 - 884x. 


\section{Loneliness, Self Esteem and Depression among Elderly People of Kashmir}

Lilleen, C. (1998). Loneliness: an epidemic in modern society. Journal of Advanced Nursing 28, 762-770.

Lim, L. L., \& Kua, E (2011). Living Alone, Loneliness, and Psychological Well-Being of Older Persons in Singapore. Current Gerontology and Geriatrics Research, Article ID 673181, 9 pages.Retriewed from http://dx.doi.org/10.1155/2011/673181.

Nor Yaacob, S., Juhari, R., Abu Talib,M. \& Uba, I. (2009). Loneliness, stress, self esteem and depression Among Malaysian Adolescents. Journal of humanity bills. Faculty of Human Ecology, University Putra Malaysia.

Orth, U. \& Robins, R. W. (). Understanding the Link Between Low Self-Esteem and Depression.Current Directions in Psychological Science, 22(6), 455 -460.

Peplau, L. A., \& Perlman, D. (1982). Perspectives on loneliness. In L. A. Peplau \& D. Perlman (Eds.), Loneliness: A sourcebook of current theory, research and therapy (pp. 1-18). New York, NY: A Willey-Interscience Publication.

Rusell, D. Peplau, L. A. \& Ferguson,M. L (1978). Developing a Measure of Loneliness. Journal of Personality Assessment, 42(3), 290-294.

Sevil, U., Ertem, G., Kavlak, O. \& Coban, A. (2006). The loneliness level of patients with gynecological cancer. International Journal of Gynecological Cancer 16, 472-477.

Singh, B., Kiran, U. V. (2013). Loneliness among elderly women. International Journal of Humanities and Social Science Invention, 2(2), 10-14.

Stek, M. L., Vinkers, D. J., Gussekloo, J., Beekman, A. T. F., van der Mast, R. C. \& Westendorp, R. G. J. (2005). Is depression in old age fatal only when people feel lonely? American Journal of Psychiatry, 162, 178-180.

Thomopoulou I., Thomopoulou D. and Koutsouki, D. (2010). The differences at quality of life and loneliness between elderly people. Biology of exercise. Vol 6.2

Tilvis, R., Pitkala, K., Jolkkonen, J. \& Strandberg, T. (2000). Feelings of loneliness and 10-year cognitive decline in the aged population. Lancet 356, $77-78$.

Van Baarsen, B., Snijders, T. A. B., Smit, J. H., \& Van Duijin, M. A. J. (2001). Lonely but not alone: Emotional isolation and social isolation as two distinct dimension of loneliness in older people. Educational and Psychological Measurement, 61, 119-135.

Yesavage, J. A., Brink, T. L., Rose, T. L., et al. (1983). Development and validation of a geriatric depression rating scale: a preliminary report. J Psych Res. 17, 27.

Yizengaw, S. S \& Ebiresilus, A. G. (2014). Psychological challenges of elders in gondar, north west Ethiopia. Innovare journal of social sciences, 2 (4).

How to cite this article: A Ahmad, M Altaf, K Jan (2016), Loneliness, Self Esteem and Depression among Elderly People of Kashmir, International Journal of Indian Psychology, Volume 3, Issue 4, No. 59, ISSN 2348-5396 (e), ISSN: 2349-3429 (p), DIP: 18.01.072/20160304, ISBN: 978-1-365-26307-1 